\title{
Bartoli Michel, Louis de Froidour (1626-1685), Notre
} héritage forestier

Collection « les dossiers forestiers ", $n^{\circ} 23$, Paris, Office National des Forêts, 2012, 220 p.

Xavier Rochel

\section{CpenEdition}

\section{Journals}

Édition électronique

URL : https://journals.openedition.org/geohist/1329

DOI : $10.4000 /$ geohist. 1329

ISSN : 2264-2617

Éditeur

Association française de la Revue de géographie historique

Référence électronique

Xavier Rochel, « Bartoli Michel, Louis de Froidour (1626-1685), Notre héritage forestier », Revue de géographie historique [En ligne], Comptes-rendus, mis en ligne le 20 novembre 2013, consulté le 12 juin 2021. URL : http://journals.openedition.org/geohist/1329 ; DOI : https://doi.org/10.4000/geohist.1329

Ce document a été généré automatiquement le 12 juin 2021.

\section{(c) (i) (3) $\Theta$}

Ce(tte) œuvre est mise à disposition selon les termes de la Licence Creative Commons Attribution Pas d'Utilisation Commerciale - Pas de Modification 4.0 International. 


\section{Bartoli Michel, Louis de Froidour (1626-1685), Notre héritage forestier}

Collection « les dossiers forestiers », $n^{\circ} 23$, Paris, Office National des Forêts, 2012, 220 p.

\section{Xavier Rochel}

\section{RÉFÉRENCE}

Bartoli Michel, Louis de Froidour (1626-1685), Notre héritage forestier, Collection « les dossiers forestiers », n² 23, Paris, Office National des Forêts, 2012, 220 p.

1 Louis de Froidour est l'un des personnages les plus éminents de l'histoire forestière française. Dans l'épisode de très grande portée qu'est la réformation " colbertienne ", Froidour incarne le versant administratif et technique du grand bouleversement des années 1660-1670; il est celui que l'Histoire retient généralement pour illustrer les difficultés rencontrées par le pouvoir royal dans l'application d'un droit forestier unifié et d'une politique forestière cohérente, au sein d'un Etat qui était alors encore bien mal cimenté. Bon nombre de chercheurs, parmi lesquels Michel Devèze, ont déjà étudié et présenté le personnage et son action.

2 Michel Bartoli, forestier de formation, mais aussi historien prolifique, est l'auteur de multiples publications sur l'histoire des forêts et des forestiers. Il apporte ici une monographie qui, sans nul doute, sera très largement diffusée et appréciée, puisqu'elle n'est pas commercialisée mais se trouve librement téléchargeable sur le site de l'office National des Forêts. L'ouvrage gênera donc peut-être les tenants irréductibles du format papier, tandis que les férus du numérique apprécieront les facilités offertes par le PDF, où la recherche de mots clés est par exemple particulièrement facile, malgré un volume écrit assez considérable - 220 pages au total.

3 L'ouvrage est clairement divisé : une première partie constitue une biographie très classique, une seconde expose « la méthode Froidour » dans son activité réformatrice, une troisième évoque la sylviculture et une quatrième, l'aménagement des forêts. La 
cinquième et dernière partie est consacrée à "l'héritage forestier " lié à Froidour. Le tout est agrémenté de documents pertinents, mais peut-être trop fortement dominés par les reproductions de documents d'archives, où les géographes remarqueront avec plaisir quelques croquis et plans des années 1660 et 1670, et regretteront l'absence de toute carte relative à l'activité du grand forestier, ne serait-ce qu'une représentation sommaire du territoire concerné.

Né dans l'Aisne, Louis de Froidour était un homme du Nord, qui fit ses premières armes dans le Bassin parisien. Grâce à la protection de Colbert, sa carrière fut brillante malgré des origines roturières. En 1666, il fut chargé d'appliquer la grande réformation " colbertienne » dans la grande maîtrise de Toulouse, sur une très vaste région étendue du Pays Basque au Vivarais. Soumettre une forêt, ou un ensemble de forêts à une " réformation » consistait alors en une opération complexe. Il s'agissait d'inventorier et cartographier les surfaces boisées existantes; d'en évaluer l'état et la valeur; de vérifier dans quelle mesure les communautés rurales pouvaient ou non en profiter; d'édicter pour l'avenir des règles de gestion plus ou moins strictes. Bien entendu, l'opération prenait une tournure judiciaire, car les abus constatés devaient être réprimés.

5 Arrivé sur place, Froidour se heurta à de multiples reprises à des obstacles inattendus. Les forêts étaient bien différentes de celles du Bassin Parisien pour lesquelles la législation avait été pensée ; on note avec intérêt ce passage transcrit par l'auteur, où Froidour fait le récit de sa première rencontre avec les forêts "plantées de sapins (...) cette sorte d'arbres (...) droits comme des flèches et sans branches qu'au houppier » (p. 109). Les structures politiques et sociales étaient elles aussi particulières; des communautés solidaires et des seigneurs puissants étaient prêts à s'opposer, y compris de vive force, aux tentatives d'intrusion du pouvoir royal. Enfin, plus encore que dans le Nord du royaume, les fonctions de la forêt mêlaient production de bois et pratiques agraires : le pastoralisme surtout, ainsi que les «artigues » et autres cultures de marge faisaient de l'espace forestier un embrouillamini paysager et fonctionnel où la « rigueur des ordonnances » peinait à trouver sa place.

Quelle fut l'oeuvre de Louis de Froidour dans ce contexte difficile? L'homme était sévère, comme il sut le prouver face aux officiers corrompus; mais il savait aussi être pragmatique. Il ne tomba pas dans le piège d'une application aveugle des règles du taillis sous futaie dans des forêts montagnardes souvent résineuses, où la futaie jardinée seule pouvait donner de bons résultats. Il accepta, bon gré mal gré, la tradition pastorale en forêt. Par une approche souple et sensée des réalités du temps et du lieu, il contribua à ce que l'irruption d'un pouvoir centralisé ne soit pas trop mal ressentie et à ce qu'elle puisse, en quelque sorte, s'enraciner dans la durée. N'opposons pas sans nuance l'approche de Froidour à celle réputée plus rigide des forestiers du XIXe siècle : bien des « hussards verts » surent, comme leur prédécesseur du XVIIIe siècle, composer avec les exigences des populations montagnardes, et se montrer bien plus pragmatiques que ne le prétend une légende noire. 